\title{
The Survival of Haloferax mediterranei under Stressful Conditions
}

\author{
Laura Matarredona $^{1}$ (D), Mónica Camacho ${ }^{1}$, Basilio Zafrilla ${ }^{1}$, Gloria Bravo-Barrales ${ }^{2}$, Julia Esclapez ${ }^{1,2}$ (D) \\ and María-José Bonete $1, *$ (D)
}

1 Agrochemistry and Biochemistry Department, Biochemistry and Molecular Biology Area, Faculty of Science, University of Alicante, Ap 99, 03080 Alicante, Spain; lauramata1996@gmail.com (L.M.); camacho@ua.es (M.C.); basilio.zafrilla@ua.es (B.Z.); julia.esclapez@ua.es (J.E.)

2 Biotecnología Arauco SpA, Arauco 4210000, Chile; gloriabravobarrales@gmail.com

* Correspondence: mijbonete@ua.es; Tel.: +34-965-903-880

Citation: Matarredona, L.; Camacho, M.; Zafrilla, B.; Bravo-Barrales, G.;

Esclapez, J.; Bonete, M.-J.

The Survival of Haloferax mediterranei under Stressful Conditions. Microorganisms 2021, 9, 336. https://doi.org/10.3390/ microorganisms 9020336

\section{Academic Editor:}

Cristina Sánchez-Porro

Received: 23 December 2020

Accepted: 3 February 2021

Published: 8 February 2021

Publisher's Note: MDPI stays neutral with regard to jurisdictional claims in published maps and institutional affiliations.

Copyright: (c) 2021 by the authors. Licensee MDPI, Basel, Switzerland. This article is an open access article distributed under the terms and conditions of the Creative Commons Attribution (CC BY) license (https:// creativecommons.org/licenses/by/ $4.0 /)$.

\begin{abstract}
Haloarchaea can survive and thrive under exposure to a wide range of extreme environmental factors, which represents a potential interest to biotechnology. Growth responses to different stressful conditions were examined in the haloarchaeon Haloferax mediterranei R4. It has been demonstrated that this halophilic archaeon is able to grow between 10 and $32.5 \%(w / v)$ of sea water, at $32-52{ }^{\circ} \mathrm{C}$, although it is expected to grow in temperatures lower than $32{ }^{\circ} \mathrm{C}$, and between 5.75 and 8.75 of $\mathrm{pH}$. Moreover, it can also grow under high metal concentrations (nickel, lithium, cobalt, arsenic), which are toxic to most living beings, making it a promising candidate for future biotechnological purposes and industrial applications. Inductively Coupled Plasma Mass Spectrometry (ICP-MS) analysis quantified the intracellular ion concentrations of these four metals in $H f x$. mediterranei, concluding that this haloarchaeon can accumulate $\mathrm{Li}^{+}, \mathrm{Co}^{2+}, \mathrm{As}^{5+}$, and $\mathrm{Ni}^{2+}$ within the cell. This paper is the first report on $H f x$. mediterranei in which multiple stress conditions have been studied to explore the mechanism of stress resistance. It constitutes the most detailed study in Haloarchaea, and, as a consequence, new biotechnological and industrial applications have emerged.
\end{abstract}

Keywords: Haloferax; stress; growth rate; doubling time; metals; Archaea

\section{Introduction}

Over the years, environmental stress has impacted all three domains of life, causing a devasting impact on growth. Microbial communities have evolved and survived through exposure to stressful conditions such as low/high solar radiation, extreme temperatures, oxidative stress, $\mathrm{pH}$ variations, salinity changes, heavy metals, or desiccation hydration cycles [1,2]. To survive in these conditions, organisms must adapt by shifting away from their optimum growth conditions. During a stress response, cells change from a growth state to a survival-state to return to homeostasis and avoid damage; consequently, the growth rate observed by optical density decreases.

In the last decades, extremophilic microorganisms have gained increasing attention in biotechnological applications as well as in bioremediation processes due to their unique metabolic capabilities, the production of stable enzymes under extremely hostile conditions, and unique biomaterials and/or secondary metabolites. Thermophilic and acidophilic microorganisms have been used extensively in valuable industrial applications such as biomining, industrial pollutant treatments, or as a source of enzymes. However, halophiles are under-represented in biotechnology [3-5]. At the time of writing this article, a small number of analyses have been carried out to study hypersaline environments, despite being distributed in a relatively large area around the world [6]; therefore, their knowledge is highly limited. Determining the in vivo behavior of a haloarchaeon and its gene expression in response to environmental variations is vital to understand how it adapts and which transcriptional changes occur to survive the ecosystem dynamics in which it 
is found. In the last decade, most research has pointed out that Haloferax mediterranei is among the best-known halophilic microorganisms belonging to the Archaea domain, and it has awakened the interest of many scientists. It can be used as a model organism for studying tolerance to environmental stress agents because its comprehensive knowledge in terms of biochemistry and molecular biology are widely known [7]. Hfx. mediterranei has several remarkable characteristics: it grows on defined media or complex media and is able to use a wide variety of carbon sources [8,9]; it has better growth rates than other known members of the Halobacteriaceae family [10,11]; it has a wide range of salt tolerance [12]; and its growth can be aerobic or anaerobic using different organic and inorganic sources [13]. Thanks to all these advantages, it is interesting to expand the knowledge on this organism and to find biotechnological and industrial interest applications because of its capacity to produce secondary metabolites [14,15]; environmental interest is also relevant including bioremediation of saline wastewaters generated from chemical, pharmaceutical, agricultural, and aquicultural industries [16-18]. Moreover, previous studies have shown that this haloarchaeon could be an attractive microorganism in terms of bioremediation as it can grow in areas with high salinity, nitrate, and nitrite to repair the damage caused by the excessive use of fertilizers used in agriculture [19].

A growing interest in climate change has emerged in recent years, and microorganisms have started to be affected due to an increase in extreme changes caused by global warming. In the case of hypersaline environments, which are often contaminated due to urbanization, industrialization, or mining, the increasing evaporation of water due to the high temperatures is causing a noticeable increase in heavy metals to toxic concentrations in these habitats. Under these conditions, most organisms are not able to deal with these rapid changes because they need optimal conditions to maintain their growth, while some microorganisms like extremophiles can tolerate and adapt to these extreme situations [20]. Therefore, understanding how $H f x$. mediterranei adapts in nature is an essential first step to improve resiliency to climate variability.

The Mediterranean area, where Hfx. mediterranei was first isolated, is considered as extremely vulnerable to global warming and future climate extreme scenarios [21,22]. This region is described as a hotspot due to the changes in the mean and seasonal variability of temperature and precipitation [23]. As part of climate change, this haloarchaeon can subsist against extreme climatic events such as hot or cold individual days, sudden rains that increase the volume of water present in the saltern ponds (decreasing the salinity percentage), nutrient shortages, or the wide variability in ultraviolet radiation. All these intense stresses cause considerable harm to microbial communities. Most researchers working in the area of climate change have supported the claim that anthropogenic activities are causing significant effects on climate forcing [24] and the environment, which endanger the life of plants and animals, and that this plays a substantial role in the destruction of much of the biodiversity and natural ecosystems $[25,26]$. In contrast, the effect of climate change is poorly studied in microorganisms such as bacteria and archaea despite being one of the strong supporters of the biosphere [27].

To uncover more about the archaeal stress response, this article provides an overview of the critical factors influencing the growth of the model haloarchaeon Hfx. mediterranei under different stress conditions. To date, there is scarce information on the in vitro analyses of this haloarchaeon in response to different stress conditions. Therefore, this is the first study to give experimental evidence regarding the tolerance of this microorganism to the tested stress conditions. Interactions among microorganisms in saline/hypersaline ecosystems can be significantly influenced by the shifts in temperature, $\mathrm{O}_{2}$ concentration, salinity changes, toxic and heavy metals, $\mathrm{pH}$ values, and nutrient supply due to the ongoing global climate change. The present work will advance the study of the Archaea domain and the field of microbial ecology and environmental interest including bioremediation. 


\section{Materials and Methods}

\subsection{Strain and Culture Media}

Hfx. mediterranei strain R4 (ATCC $33500^{\mathrm{T}}$ ) was grown at $42{ }^{\circ} \mathrm{C}$ in complex media $(\mathrm{Hm}-\mathrm{CM})$ containing a $20 \%(w / v)$ mixture of inorganic salts [9] and $0.5 \%(w / v)$ yeast extract per litter. The $\mathrm{pH}$ of the culture medium was adjusted to 7.3 with $\mathrm{NaOH}$.

Hfx. mediterranei defined medium (Hm-DM) contained a concentration of $20 \%(w / v)$ sea water and $20 \mathrm{mM} \mathrm{NH}_{4} \mathrm{Cl}(\mathrm{pH}$ 7.3). After autoclaving and cooling, it was supplemented with $50 \mathrm{mM}$ MOPS (3-(N-morpholino)propane sulfonic acid), $\mathrm{pH} 7.3,0.03 \mathrm{mM} \mathrm{FeCl}$, $7.5 \mathrm{mM} \mathrm{CaCl}_{2}, 27.75 \mathrm{mM}$ glucose, and $1 \mathrm{mM} \mathrm{KH}_{2} \mathrm{PO}_{4}$ per liter. All microbial cultures were incubated aerobically at $42{ }^{\circ} \mathrm{C}$ with shaking $(220 \mathrm{rpm}$ ) unless otherwise stated. Cell growth was quantified by measuring the optical density at $600 \mathrm{~nm}$ wavelength $\left(\mathrm{OD}_{600}\right)$ at regular intervals (6-10 h depending on the culture's growth rate of the culture) until reaching the stationary phase.

\subsection{Stress Conditions}

The current investigation involved sampling and analyzing five different stress conditions: salinity, temperature, $\mathrm{pH}, \mathrm{H}_{2} \mathrm{O}_{2}$, and metal stress. $\mathrm{Hm}-\mathrm{DM}$ was used as basal culture media in all five experiments, varying in each one only by one parameter (sea water concentration, temperature, $\mathrm{pH}, \mathrm{H}_{2} \mathrm{O}_{2}$, concentration, metal concentration).

To analyze the effect of salt concentration on $H f x$. mediterranei growth, cells grown in Hm-DM with a range of sea water (SW) between 10 and 32.5\% (10, 12.5, 15, 17.5, 20, $22.5,25,27.5,30$, and $32.5 \% \mathrm{SW}$ ) without modifying the ion ratios were tested. To induce temperature stress, growth was assessed at a temperature range of $32-52{ }^{\circ} \mathrm{C}(32,37,42$, 47 , and $52^{\circ} \mathrm{C}$ ) in $\mathrm{Hm}$-DM. To study $\mathrm{pH}$ stress in $\mathrm{Hfx}$. mediterranei, the $\mathrm{pH}$ of each culture medium (Hm-DM) was adjusted differently, varying in a range between 5.75 and 8.75 ( $\mathrm{pH}$ values were $5.75,6.0,6.25,6.5,6.75,7.0,7.25,7.5,7.75,8.0,8.25,8.5$, and 8.75). Oxidative stress was induced by adding $\mathrm{H}_{2} \mathrm{O}_{2}$ ranging from 2 to $14 \mathrm{mM}(2,4,6,810,12$, and $14 \mathrm{mM})$ to cultures of $H f x$. mediterranei grown in $\mathrm{Hm}-\mathrm{DM}$ at $\mathrm{OD}_{600}$ of 0.8 (mid-exponential phase), and the cells were cultivated for another $48-60 \mathrm{~h}$. For metal resistance analysis, four metals that are toxic to most living beings at high concentrations were tested: nickel $\left(\mathrm{Ni}^{2+}\right)$ $0.4-1.6 \mathrm{mM}(0.4,0.8,1.2$, and $1.6 \mathrm{mM})$; arsenic $\left(\mathrm{As}^{5+}\right) 2-10 \mathrm{mM}(2,4,6,8$, and $10 \mathrm{mM})$; cobalt $\left(\mathrm{Co}^{2+}\right)$ 0.2-1.2 mM $(0.2,0.4,0.6,0.8,1.0$, and $1.2 \mathrm{mM})$; and lithium $\left(\mathrm{Li}^{+}\right) 0.5-500 \mathrm{mM}(0.5,2$, $5,20,50,250$, and $500 \mathrm{mM}$ ). Metal salts used in the study were $\mathrm{NiSO}_{4}, \mathrm{Na}_{2} \mathrm{HAsO}_{4}, \mathrm{CoCl}_{2}$, and $\mathrm{LiCl}$.

Three independent biological replicates were performed for each condition to ensure reproducibility, and a control condition (Hm-DM with $20 \% \mathrm{SW}, \mathrm{pH} 7.3,42^{\circ} \mathrm{C}$ ) was maintained. In the $\mathrm{pH}$ stress analysis, the $\mathrm{pH}$ of the cultures was measured daily to check the stability during growth. The starting $\mathrm{OD}_{600}$ of all the cultures was set to 0.02 , and the lag phase, $\log$ phase, and stationary phase were statistically analyzed and compared among groups.

\subsection{Specific Growth Rate and Doubling Time}

Specific growth rate $(\mu)$ and doubling time (d.t.) were calculated by using the following equations:

$$
\begin{gathered}
\mu=\frac{\ln X-\ln X o}{t-t o} \\
\text { d.t. }=\frac{\ln 2}{\mu}
\end{gathered}
$$

$X$ and $X o$ represent cell concentration at the beginning of the exponential phase and after a specific time interval, respectively. 


\subsection{Statistical Analysis}

Statistical analysis was performed using GraphPad Prism (Version 8). All values in the figures are expressed as the mean of three replicates \pm the standard deviation. Brown Forsythe and Welch ANOVA tests with Dunnett T3 multiple comparison tests were used to determine whether there were any statistical differences between each stress condition's mean with the mean of the control. In all of the analyses, a value of $p<0.05$ was considered significant.

\subsection{Sample Treatment for Inductively Coupled Plasma Mass Spectrometry (ICP-MS)}

The intracellular concentrations of the four metals' ions $\left(\mathrm{Co}^{2+}, \mathrm{Li}^{+}, \mathrm{Ni}^{2+}\right.$, and $\left.\mathrm{As}^{5+}\right)$ were analyzed using ICP-MS. Hfx. mediterranei was grown in Hm-DM at selected concentrations $\left(\mathrm{Co}^{2+} 0.2\right.$ and $1.2 \mathrm{mM}, \mathrm{As}^{5+} 4 \mathrm{mM}, \mathrm{Ni}^{2+} 0.5$ and $1.2 \mathrm{mM}, \mathrm{Li}^{+} 12,50,250$, and $\left.500 \mathrm{mM}\right)$. Briefly, cells were cultured in Hm-DM until the stationary phase was reached. The cells were pelleted by centrifugation at $10,000 \times g$ for $10 \mathrm{~min}$, and the media were removed. Several washes with $20 \%$ sterile sea water were performed. Cell samples were subjected to acidic mineralization to oxidize the organic matter, solubilize all metals, and simplify the matrix. The samples were weighed on an analytical balance and placed in acid-washed $15 \mathrm{~mL}$ quartz digestion vials with Teflon-lined caps, to which $4 \mathrm{~mL}$ of $\mathrm{HNO}_{3}$ and $1 \mathrm{~mL}$ of $\mathrm{H}_{2} \mathrm{O}$ were added. The instrument used to perform the mineralization was the Ultrawave digestor from Milestone. The microwave program consisted of a ramp to $100{ }^{\circ} \mathrm{C}$ in $5 \mathrm{~min}$, $15 \mathrm{~min}$ from $100{ }^{\circ} \mathrm{C}$ to $170{ }^{\circ} \mathrm{C}, 10 \mathrm{~min}$ from $170{ }^{\circ} \mathrm{C}$ to $240{ }^{\circ} \mathrm{C}$, and a holding time of $15 \mathrm{~min}$ at $240^{\circ} \mathrm{C}$. Once the samples were mineralized, sample volumes were brought to $15 \mathrm{~mL}$ with Milli-Q water. A control cell extract (Hfx. mediterranei grown in Hm-DM without any metals) was treated identically and assayed.

\subsection{Quantification of Metal Content by ICP-MS}

The selected elements $\mathrm{Co}^{2+}, \mathrm{Li}^{+}, \mathrm{Ni}^{2+}$, and $\mathrm{As}^{5+}$, were determined by ICP-MS in the Research Technical Services of Alicante University. Different concentration solutions of PlasmaCal SCP33MS, SCP SCIENCE were prepared in 1\% nitric acid and analyzed as calibration standards to quantify the concentration of the mentioned elements using an Agilent 8800 inductively coupled plasma mass spectrometer triple quadrupole (ICP-MS QQQ, Agilent Technologies, Las Rozas, Madrid, Spain) equipped with a micromist concentric nebulizer (Meinhard, MicroMist, Meinhard), a Peltier cooled double-pass spray chamber, standard torch, and autosampler. Data analysis was performed using the Mass Hunter workstation for ICP-MS QQQ software (Agilent Technologies, Las Rozas, Madrid, Spain) to determine the total concentration of elements in sample solutions. Two tune modes were used sequentially to ensure proper ionization and interference removal. The internal standard was also used to correct signal drift.

\section{Results and Discussion}

\subsection{Salinity Stress}

A widespread form of stress observed in the Mediterranean area involves a change in external osmolarity due to extended periods of rain or drought. It was determined that members of the Haloarchaea class require a salt concentration of at least $10 \%(w / v)$ for growth and can survive up to $35 \%(w / v)$ in their natural environment, showing a significant vulnerability when the external salinity is decreased $[8,9,28]$. In this study, Hfx. mediterranei strain R4 could grow optimally in Hm-DM with a salt concentration between 10 and 32.5\% $(w / v)$. This suggests that its osmoregulatory responses are efficient to maintain positive growth over a wide range of salinity. Therefore, to analyze if the salinity stress substantially impacted cell growth, the three phases (lag phase, log phase, and stationary phase) of the sigmoid function were statistically analyzed and compared among groups, where the most significant were found in the stationary phase (Figure S1). Hence, mean values of optical density at $600 \mathrm{~nm}$ of the stationary phases are shown in Figure 1a, highlighting that not all the cultures reached this phase at the same time. There was a significant difference in 
mean values across almost all the conditions (except 17.5 and $22.5 \%(w / v)$ ) and the control. Under $10 \%(w / v)$, no growth was detected under the assayed conditions, and a delayed growth was observed at low $\mathrm{NaCl}$ concentrations. Though it tolerated up to $10 \%$ of salt concentration, the growth was considerably less than the $20 \%$ control, and $\mathrm{OD}_{600}$ values did not reach above 0.7 (Figure 1a). Over a wide range of salt concentrations, from 27.5 to $32.5 \%$ $(w / v)$, the growth curves were almost identical, and growth rates were relatively constant (Figure 1b). This result indicates that this microorganism has the necessary osmoadaptation for dealing with saturating salt conditions; in fact, good growth still occurs.

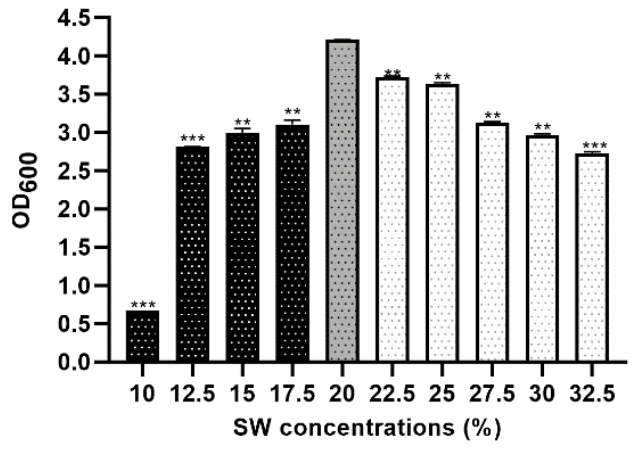

(a)

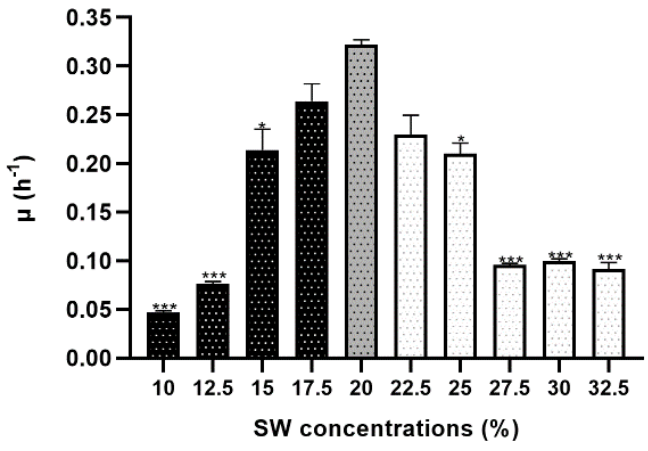

(b)

Figure 1. Effect of salinity stress on the growth profile of Hfx. mediterranei R4 grown in Hm-DM. Data are based on three independent cultures. (a) Maximum $\mathrm{OD}_{600}$ in stationary phase (reached at different times). (b) Average growth rate. Plotted values are the mean of triplicate measurements, and error bars represent $\pm \mathrm{SD} .{ }^{*} p \leq 0.05 ;{ }^{* *} p \leq 0.01 ;{ }^{* *} p \leq 0.001$. In grey, the control; in black, lower concentrations of SW\%; in white, higher concentrations of SW\%.

The specific growth rate and doubling time were calculated in all salinity stress conditions. The control (20\%) reached the best growth rate value compared to the other salinity values, achieving $0.322 \mathrm{~h}^{-1}$ (Figure $1 \mathrm{~b}$ ). Value $0.322 \mathrm{~h}^{-1}$ was compared with an assay reported by Rodríguez-Valera, who concluded that the optimum growth rate between 10 to $35 \%$ was $20 \%$ with a value of $0.12 \mathrm{~h}^{-1}$ [29]. The value of $0.12 \mathrm{~h}^{-1}$ was worse than that of $0.322 \mathrm{~h}^{-1}$ because the growing conditions were not the same, despite containing the same amount of inorganic salts. In the experiment performed by Rodríguez-Valera, cultures were incubated at $38^{\circ} \mathrm{C}$, the $\mathrm{pH}$ was adjusted to 7.0 , and the specific growth rate was calculated in a different way, taking into account all the growing curves; in our work, only the exponential phase data were used.

Table 1 represents all doubling time values, showing significant differences in almost all the cultures. The medium composition and the temperature influenced all these results.

Table 1. Doubling time for $H f x$. mediterranei under salinity stress conditions.

\begin{tabular}{cccc}
\hline \%SW & d.t. $(\mathbf{h}) *$ & $\boldsymbol{p}$-Value & Summary \\
\hline 10 & $14.8 \pm 0.5$ & $<0.001$ & $* * *$ \\
12.5 & $9.1 \pm 0.2$ & $<0.001$ & $* * *$ \\
15 & $3.4 \pm 0.2$ & 0.037 & ns \\
17.5 & $2.7 \pm 0.2$ & 0.148 & Control \\
20 & $2.15 \pm 0.03$ & 0.138 & $*$ \\
22.5 & $3.0 \pm 0.3$ & 0.037 & $* * *$ \\
25 & $3.3 \pm 0.2$ & $<0.001$ & $* * *$ \\
30 & $7.2 \pm 0.1$ & $<0.001$ & $* * *$
\end{tabular}

ns: $p>0.05 ;{ }^{*} p \leq 0.05 ;{ }^{* * *} p \leq 0.001 .{ }^{*} H f x$. mediterranei growth in liquid culture was assessed by optical density at $600 \mathrm{~nm}$, and doubling times during exponential phase growth were calculated as described in the Materials and Methods section. 
The effect of salinity concentration on the growth of Haloarcula marismortui RR12 was also studied, and the results showed that the optimal growth of this haloarchaeon was reached at $20 \%$ SW [16] as Hfx. mediterranei. However, the comparison of growth curves between both halophilic microorganisms showed differences since Hfx. mediterranei reached higher $\mathrm{DO}_{600}$ values independently of SW concentration, except in $10 \% \mathrm{SW}$. Moreover, the generation times of $H f x$. mediterranei cultures (Table 1) were lower than those of Hal. marismortui not only at a low salt concentration (10\%), but also at high concentrations (30\%). These characteristics make Hfx. mediterranei a promising microorganism for biotechnological applications compared to other halophiles because it can generate more biomass in a shorter time.

Deciphering the salt tolerance of Hfx. mediterranei will contribute to better understanding resistance and defense against toxicity at a molecular level. The high salt concentrations that this haloarchaeon can tolerate are lethal to most living organisms.

\section{2. $\mathrm{pH}$ Stress}

Not only are Haloarchaea exposed to salinity changes, but they are also predisposed to changes in $\mathrm{pH}$. In this study, Hfx. mediterranei was exposed to several different $\mathrm{pH}$ values, ranging from the lower (acidic $\mathrm{pH}$ ) to upper (alkaline $\mathrm{pH}$ ) limits for the microorganism. Apart from the composition of the culture media (Hm-DM), $\mathrm{pH}$ is another important requirement for optimum growth. This halophilic microorganism grows optimally or very well at neutral $\mathrm{pH}$ values of 7.2-7.4. In this study, $\mathrm{pH}$ values ranging from 5.75 to 8.75 were tested; this $\mathrm{pH}$ range was within the ranges previously reported for other species from the same genera [30,31]. During growth, the $\mathrm{pH}$ was measured to verify its stability. At $\mathrm{pH}$ below 5.75 and above 8.75, Hfx. mediterranei was unable to survive and grow.

Moreover, $\mathrm{OD}_{600}$ monitoring indicated a strong impact of low $\mathrm{pH}$ stress on cell growth, whereas high $\mathrm{pH}$ values caused relatively minor changes; thus, Hfx. mediterranei tolerates high $\mathrm{pH}$ better than low $\mathrm{pH}$ (Figure 2a and Figure S2). To analyze the impact of changing $\mathrm{pH}$ values, the maximum optical density reached at different times by cultures was statistically analyzed and compared. A strong impact was detected in the stationary phases when the $\mathrm{pH}$ was far away from the optimal $\mathrm{pH}$, particularly in 5.75, 6.0, 8.5, and 8.75 (Figure 2a).

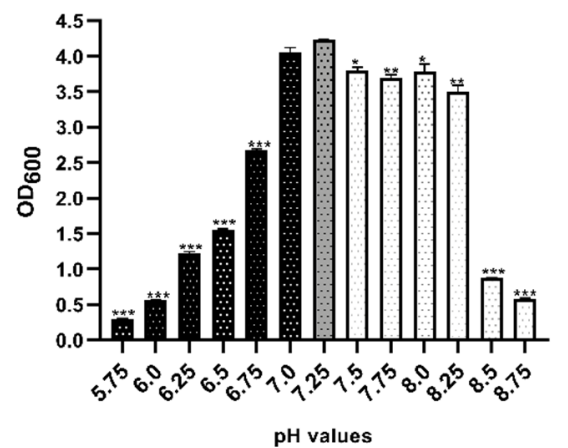

(a)

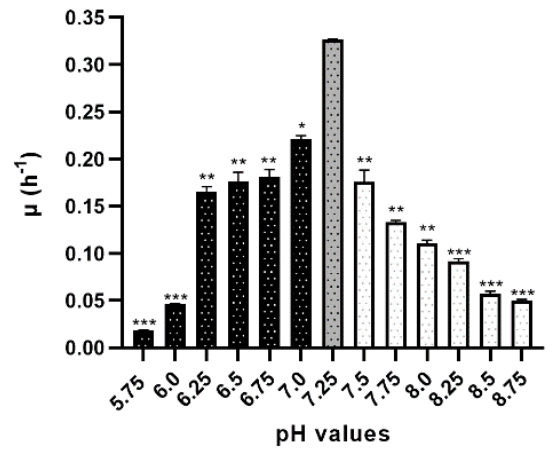

(b)

Figure 2. Effect of $\mathrm{pH}$ stress on the growth profile of Hfx. mediterranei R4 grown in Hm-DM. Data are based on three independent cultures. (a) Maximum $\mathrm{OD}_{600}$ in stationary phase (reached at different times). (b) Average growth rate. Plotted values are the mean of triplicate measurements, and error bars represent $\pm \mathrm{SD}$. ${ }^{*} p \leq 0.05 ;{ }^{* *} p \leq 0.01$; ${ }^{* *} p \leq 0.001$. In grey, the control; in black, acidic $\mathrm{pH}$; in white, alkaline $\mathrm{pH}$.

As can be seen in Figure $2 \mathrm{~b}$ and Table 2, the growth kinetics were also analyzed. The control ( $\mathrm{pH}$ 7.25) reached the best results, underscoring the importance of maintaining the $\mathrm{pH}$ value. Furthermore, even though $\mathrm{pH} 7.0$ showed no significant differences in the maximum optical density achieved by the culture (Figure 2a), significant differences were detected in terms of growth rate (Figure 2b) and doubling time (Table 2). At lower $\mathrm{pH}$ 
values, cells grew much slower than at high values of $\mathrm{pH}$. In all tested conditions, data for each $\mathrm{pH}$ value were significant among the groups and the control $(p \leq 0.05)$, as shown in Figure $2 \mathrm{~b}$ and Table 2 . These results show that although the growth was slower at extreme acidic or alkaline $\mathrm{pH}, \mathrm{H} f \mathrm{x}$. mediterranei $\mathrm{R} 4$ can grow over a wide $\mathrm{pH}$ range, and the study of its adaptation strategies may provide interesting insights into the physiology and survival mechanisms of Haloarchaea.

Table 2. Doubling time for $H f x$. mediterranei growth under different $\mathrm{pH}$ stress conditions.

\begin{tabular}{cccc}
\hline $\mathbf{p H}$ & d.t. $(\mathbf{h}) *$ & $p$-Value & Summary \\
\hline 5.75 & $36.9 \pm 0.3$ & $<0.001$ & $* * *$ \\
6.0 & $15.0 \pm 0.3$ & $<0.001$ & $* * *$ \\
6.25 & $3.9 \pm 0.1$ & 0.006 & $* *$ \\
6.5 & $4.2 \pm 0.1$ & 0.003 & $* *$ \\
6.75 & $3.13 \pm 0.05$ & 0.03 & $*$ \\
7.0 & $3.8 \pm 0.2$ & 0.004 & Control \\
7.25 & $2.15 \pm 0.03$ & - & $* *$ \\
7.5 & $5.22 \pm 0.09$ & 0.001 & $* *$ \\
7.75 & $6.3 \pm 0.2$ & 0.003 & $* *$ \\
8.0 & $4.0 \pm 0.3$ & 0.003 & $* * *$ \\
8.25 & $7.6 \pm 0.2$ & $<0.001$ & $* * *$ \\
8.5 & $12.1 \pm 0.2$ & $<0.001$ & $<0.001$ \\
8.75 & $14.0 \pm 0.3$ & $* 4$
\end{tabular}

ns: $p>0.05 ;{ }^{*} p \leq 0.05 ;{ }^{* *} p \leq 0.01 ;{ }^{* * *} p \leq 0.001 .{ }^{*} H f x$. mediterranei growth in liquid culture was assessed by optical density at $600 \mathrm{~nm}$, and doubling times during exponential phase growth were calculated as described in the Materials and Methods section.

\subsection{Temperature Stress}

Focusing on the response to changes in temperature, $H f x$. mediterranei was exposed to different temperature values to analyze its broad tolerance. In previous studies, the lowertemperature limit tested for growth was $12{ }^{\circ} \mathrm{C}$ and the upper-temperature limit tested was $55^{\circ} \mathrm{C}$ [10]. In this study, Hfx. mediterranei was able to grow in Hm-DM in a temperature range of $32-52{ }^{\circ} \mathrm{C}$. However, its optimum growth occurred at $42{ }^{\circ} \mathrm{C}$. Measurable growth was observed down to a temperature of $32{ }^{\circ} \mathrm{C}$, though growth was very slow. The growth temperature optimum and minimum for Hfx. mediterranei are typical of most Haloarchaea [10,32]. Halophiles have a slight thermophilic character due to the hot weather seasonal temperatures of the environment in which they live.

As in the other previous stress conditions, all the cultures' stationary phases were statistically compared and analyzed, highlighting that this stationary phase was the maximum growth reached at different times by cultures. There was a significant difference detected in mean values across $32,47,52{ }^{\circ} \mathrm{C}$, and the control $\left(42{ }^{\circ} \mathrm{C}\right)$ (Figure $\left.3 \mathrm{a}\right)$; therefore, the growth curves of cultures that showed a difference were displayed (Figure S3). Furthermore, focusing on growth kinetics, changes in the specific growth rates and doubling times of the groups are shown in Figure $3 b$ and Table 3 . These values were affected by changes in temperature. As shown in Figure 3b, at temperature values lower than the optimal (black bars), cells grew much lower than at high values (white bars). Moreover, the lowest growth values were found at 32 and $37^{\circ} \mathrm{C}$ with 0.02 and $0.03 \mathrm{~h}^{-1}$, respectively. 


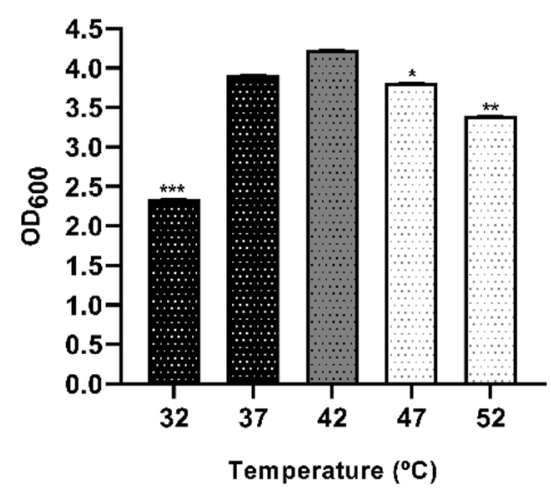

(a)

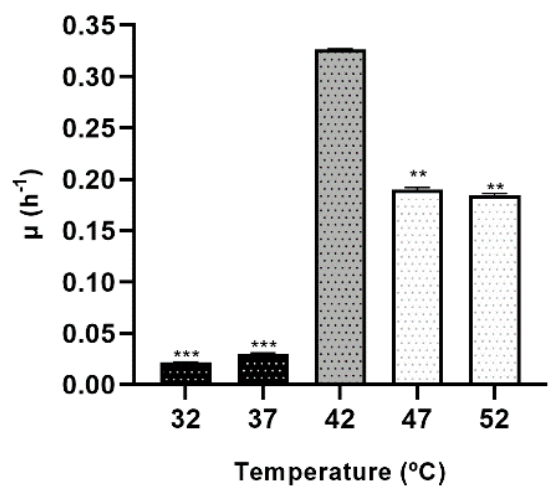

(b)

Figure 3. Effect of temperature stress on the growth profile of Hfx. mediterranei R4 grown in Hm-DM. Data are based on three independent cultures. (a) Maximum $\mathrm{OD}_{600}$ in stationary phase (reached at different times). (b) Average growth rate. Plotted values are the mean of triplicate measurements, and error bars represent $\pm \mathrm{SD} .{ }^{*} p \leq 0.05 ;{ }^{* *} p \leq 0.01$; ${ }^{* * *} p \leq 0.001$. In grey, the control; in black, lower temperatures; in white, higher temperatures.

Table 3. Doubling time of $H f x$. mediterranei growth under different temperatures.

\begin{tabular}{cccc}
\hline Temperature $\left({ }^{\circ} \mathbf{C}\right)$ & d.t. $($ h) & $p$-Value & Summary \\
\hline 32 & $31.8 \pm 0.4$ & $<0.001$ & $* * *$ \\
37 & $23.0 \pm 0.4$ & $<0.001$ & Control \\
42 & $2.13 \pm 0.03$ & - & $* *$ \\
47 & $3.65 \pm 0.04$ & 0.004 & $* *$ \\
52 & $3.75 \pm 0.03$ & 0.003 & $*$ \\
\hline
\end{tabular}

${ }^{* *} p \leq 0.01 ;{ }^{* * *} p \leq 0.001 .{ }^{*} H f x$. mediterranei growth in liquid culture was assessed by optical density at $600 \mathrm{~nm}$ and doubling times during the exponential phase growth were calculated as described in the Materials and Methods section.

In other previous studies, the minimum doubling time of $H f x$. mediterranei reported was as low as $1.20 \mathrm{~h}$ in complex medium at $47-54{ }^{\circ} \mathrm{C}$ and $2.07 \mathrm{~h}$ in defined medium at $43-51{ }^{\circ} \mathrm{C}$ [11]. These results are similar to the ones obtained in this research. As shown in Table 3, the control culture reached the lowest doubling time of $2.13 \mathrm{~h}$. This ability to survive in high temperatures makes this haloarchaeon a potential microorganism to use in biotechnological processes since its enzymes do not run the risk of denaturation.

\subsection{Oxidative Stress}

To show the resistance of $H f x$. mediterranei to oxidative stress, this hypersaline archaeon was exposed in the exponential phase to various hydrogen peroxide concentrations ranging from 2 to $14 \mathrm{mM}$. All cultures continued to grow, exhibiting differences from the nonstressed control (same medium culture without adding peroxide). At first, the growth curves were almost identical, but a significant difference was observed in the maximum optical density reached at different times (Figure 4 and Figure S4). The effect was relatively mild after the addition of hydrogen peroxide $\left(\mathrm{H}_{2} \mathrm{O}_{2}\right)$ between 2 and $8 \mathrm{mM}$, in contrast to 10-14 $\mathrm{mM}$, which led to a considerable reduction in growth, and cultures only reached an optical density of 1.0 at $600 \mathrm{~nm}$, taking into account that the hydrogen peroxide was added at 0.8 . Cells could not tolerate concentrations higher than $16 \mathrm{mM}$; therefore, no significant growth was observed. Furthermore, comparing these results with other similar previous work showed that other Haloarchaea (e.g., Hbt. salinarum NRC-1) are highly more resistant than $\mathrm{Hfx}$. mediterranei to oxidative stress. Hbt. salinarum grows in remarkably $\mathrm{H}_{2} \mathrm{O}_{2}$ stressful conditions and survives up to $25 \mathrm{mM} \mathrm{H}_{2} \mathrm{O}_{2}$, whereas $16 \mathrm{mM} \mathrm{H}_{2} \mathrm{O}_{2}$ is lethal to $H f x$. mediterranei [33]. This fact could result from differences in the thickness and composition of the S-layer between both halophilic microorganisms. Therefore, all these pieces of evidence demonstrate that $H f x$. mediterranei can grow in the presence of up to $16 \mathrm{mM}$ of $\mathrm{H}_{2} \mathrm{O}_{2}$, 
but this haloarchaeon is not able to grow if the hydrogen peroxide is added from the beginning of growth.

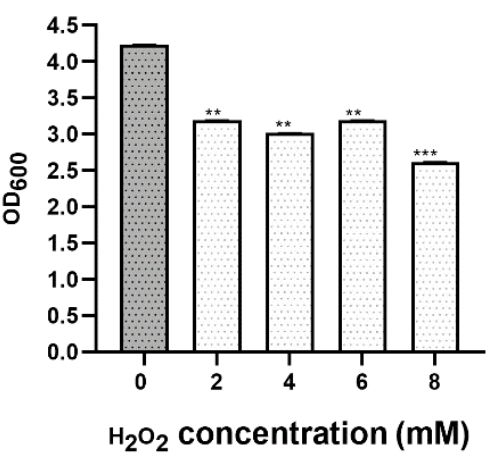

(a)

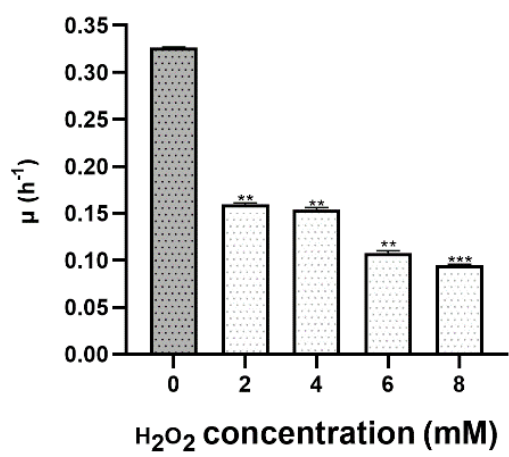

(b)

Figure 4. Effect of oxidative stress on the growth profile of Hfx. mediterranei R4 grown in Hm-DM. Data are based on three independent cultures. (a) Maximum $\mathrm{OD}_{600}$ in stationary phase (reached at different times). (b) Average growth rate. Plotted values are the mean of triplicate measurements, and error bars represent $\pm \mathrm{SD}$. ${ }^{* *} p \leq 0.01 ;{ }^{* * *} p \leq 0.001$. In grey, the control without $\mathrm{H}_{2} \mathrm{O}_{2}$; in white, with $\mathrm{H}_{2} \mathrm{O}_{2}$.

The specific growth rate and doubling time of the exponential growth phase were determined at each concentration of $\mathrm{H}_{2} \mathrm{O}_{2}$ (Figure $4 \mathrm{~b}$ and Table 4 ), using the data from the growth curve. As expected, the higher the peroxide concentration s, the slower the growth rate and the higher the doubling time. Similar values of cell growth were observed in cultures with 2 and $4 \mathrm{mM}$ of $\mathrm{H}_{2} \mathrm{O}_{2}$.

Table 4. Doubling time of $H f x$. mediterranei growth in the presence of different $\mathrm{H}_{2} \mathrm{O}_{2}$ concentrations to induce oxidative stress.

\begin{tabular}{cccc}
\hline$\left[\mathrm{H}_{\mathbf{2}} \mathbf{O}_{2}\right](\mathbf{m M})$ & d.t. $(\mathbf{h}) *$ & $p$-Value & Summary \\
\hline 0 & $2.13 \pm 0.03$ & - & Control \\
2 & $4.34 \pm 0.04$ & 0.003 & $* *$ \\
4 & $4.51 \pm 0.08$ & 0.003 & $* *$ \\
6 & $6.4 \pm 0.1$ & 0.001 & $* * *$ \\
8 & $7.3 \pm 0.1$ & $<0.001$ & $*$ \\
\hline
\end{tabular}

$\overline{* *} p \leq 0.01 ; * * * p \leq 0.001 .{ }^{*} H f x$. mediterranei growth in liquid culture was assessed by optical density at $600 \mathrm{~nm}$, and doubling times during the exponential phase growth were calculated as described in the Materials and Methods section.

\subsection{Metal Stress}

Hypersaline environments or contaminated sea waters are natural environments where few microorganisms can survive due to the high salinity. These places are also generally contaminated with heavy metals due to urban and industrial discharge. As haloarchaea can thrive in such extreme environments, they are of great importance due to their capacity to deal with metals. Most metals that are toxic to microorganisms at high concentrations are released due to anthropogenic activities such as from agricultural waste or industrial disposals. The importance of microorganisms with metabolic capabilities to tolerate salt and metals simultaneously is increasing. Hence, the current study focuses on the tolerance of Hfx. mediterranei toward nickel, cobalt, arsenic, and lithium using different concentrations of metal salts. At the time of writing this article, few essays have been carried out to study the natural susceptibility of Halobacteria to heavy metals. To analyze the sensibility of $H f x$. mediterranei to these metals, the maximum optical density reached at different times by the cultures were statistically analyzed and compared among groups and the control (non-stressed) (Figure 5). The behavior of this haloarchaeon was not homogeneous concerning all tested metals. From a general point of view, Hfx. mediterranei 
can tolerate $\mathrm{Co}^{2+}, \mathrm{As}^{5+}, \mathrm{Li}^{+}$, and $\mathrm{Ni}^{2+}$, but in different ways. The optical density was monitored, showing a strong impact of $\mathrm{Co}^{2+}$ stress on cell growth, whereas the addition of $\mathrm{Ni}^{2+}$ caused relatively minor changes. For $\mathrm{Ni}, \mathrm{H} f x$. mediterranei could grow up to $1.6 \mathrm{mM}$, reaching a maximum $\mathrm{OD}_{600}$ of 0.65 . Above $1.6 \mathrm{mM}$, no growth was detected. Therefore, the minimum inhibitory concentration of nickel tested against $H f x$. mediterranei was $1.6 \mathrm{mM}$. There was a significant difference in the mean values of the stationary phases across almost all conditions (except $0.4 \mathrm{mM}$ ) and the control (Figure 5a and Figure S5). Hfx. mediterranei showed consistent growth at all nickel concentrations, with a gradual reduction in growth with increasing nickel concentration. Other members from the same genus such as $\mathrm{Hbt}$. salinarum, Hfx. gibbonsii, Hfx. hispanicum, $H f x$. volcanii, or Hfx. vallismortis can grow up to similar concentrations [34-36]; however, Haloarcula sp. can only grow up to $0.1 \mathrm{mM}$ of $\mathrm{Ni}$ [37]. Environmental pollution of hypersaline environments with nickel and other toxic metals is due to anthropogenic activities such as industrialization [38] since these habitats act as sinks for these metals. Although more work is needed, these data are an excellent start point to use Hfx. mediterranei in bioremediation. Moreover, $\mathrm{Ni}^{2+}$ is industrially relevant since nickel-hydrogen batteries for large-scale energy storage have been acclaimed as an advanced power source [39].

Regarding the addition of $\mathrm{Co}^{2+}, \mathrm{Hfx}$. mediterranei $\mathrm{R} 4$ could not grow in concentrations of cobalt higher than $1.2 \mathrm{mM}$. When cells were exposed to 1.0 and $1.2 \mathrm{mM}$, the stationary phase was reached at an optical density around 1, showing high mortality. Independent of $\mathrm{Co}^{2+}$ concentration, the $\mathrm{OD}_{600}$ value decreased with its presence (Figure $5 \mathrm{c}$ and Figure S6). In all tested concentrations with the addition of $\mathrm{Co}^{2+}$, the growth curves showed an initial long lag phase indicating difficulties to start growing. These results are similar to the ones obtained in $H f x$. mediterranei by Nieto, who concluded that the lowest concentration of $\mathrm{Co}^{2+}$, which prevented growth, was $1 \mathrm{mM}$ [37]. Other microorganisms such as $H f x$. gibbonsii, Hfx. hispanicum, Hfx. volcanii, Hfx. vallismortis, and Haloarcula sp. also grow up to $1 \mathrm{mM}$; however, Hbt. halobium only grows up to $0.5 \mathrm{mM}$ [37]. As cobalt has been found in industrial wastewaters, its removal is essential due to its serious health effects and environmental hazard. In terms of future applications, finding out the biosorption capacity of Hfx. mediterranei for bioremediation of $\mathrm{Co}^{2+}$ from contaminated water in natural environments would be one crucial biotechnological application. In addition to being relevant in bioremediation, it is also useful in the mining industry to produce cobalt [40].

Arsenic ions are very toxic to most microorganisms, explaining the more prolonged lag phase experienced by Hfx. mediterranei. However, this haloarchaeon is not the only one that can grow in the presence of arsenic. Previous work showed that $20 \mathrm{mM}$ is the lowest metal concentration that prevented the growth of Hbt. salinarum and Hfx. volcanii [37]. In Hfx. mediterranei, all cultures had a lag phase of $48 \mathrm{~h}$ before starting to grow, and significant differences were detected in mean values across all tested concentrations (Figure 5e and Figure S7). Arsenate concentrations higher than $10 \mathrm{mM}$ were not tested because the resulting optical density was imprecise due to the medium's turbidity. However, a previous assay reported that $H f x$. mediterranei could withstand $20 \mathrm{mM}$ of arsenate [37]. Future assays should be based on studying the mechanism of arsenic resistance in Hfx. mediterranei because little work has been reported on this subject, and new industrial and biotechnological applications may appear. 


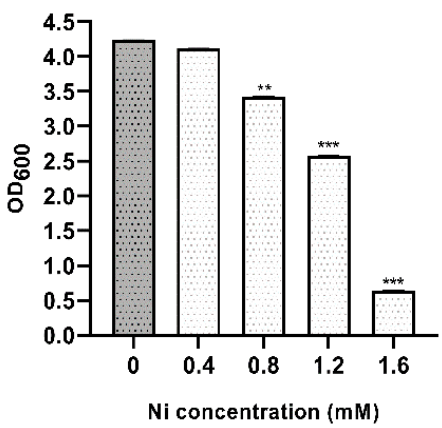

(a)

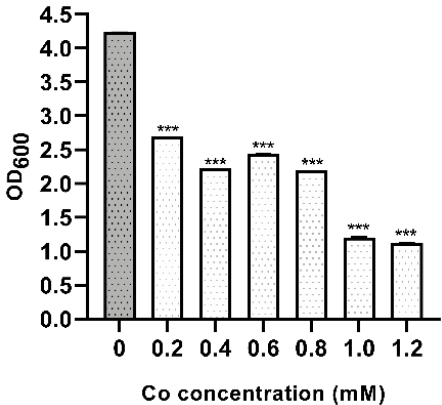

(c)

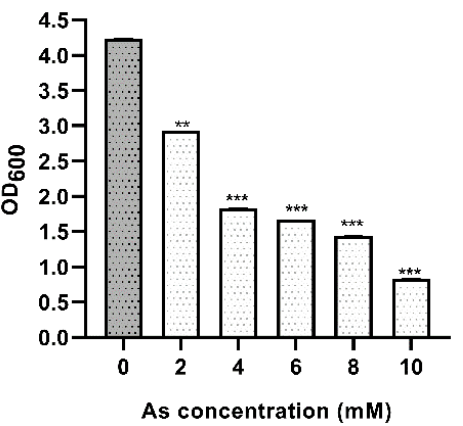

(e)

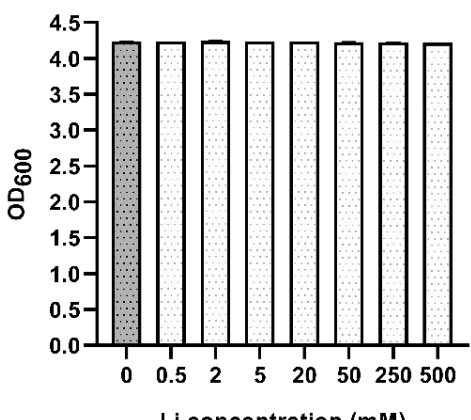

(g)

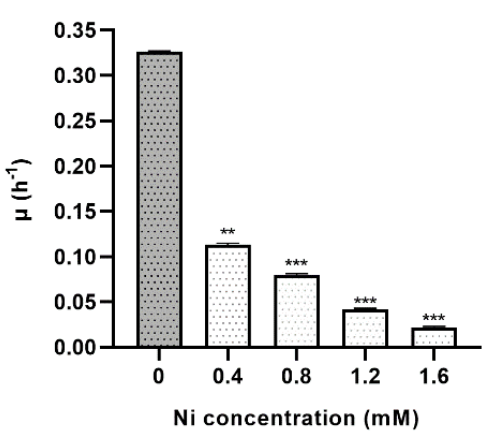

(b)

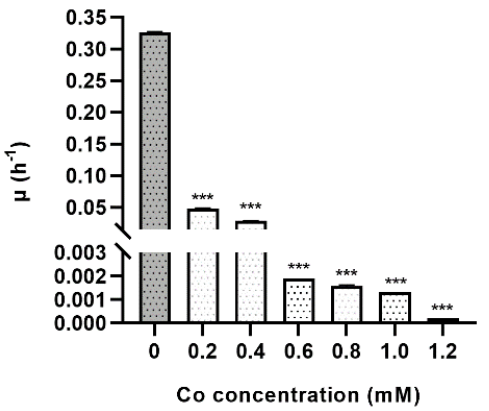

(d)

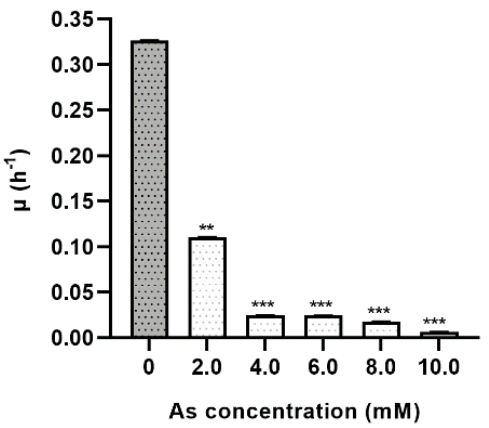

(f)

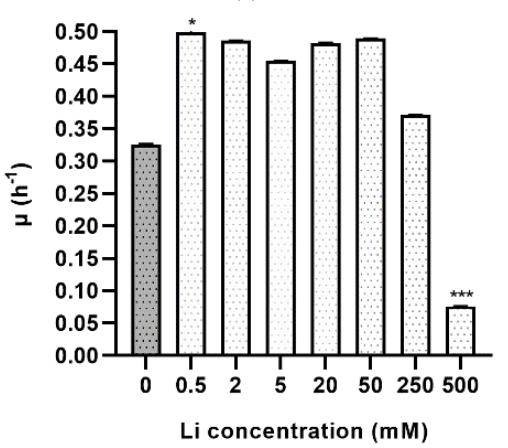

(h)

Figure 5. Effects of heavy metal stress on the growth profile of $H f x$. mediterranei R4 grown in Hm-DM. Data are based on three independent cultures. (a) Maximum $\mathrm{OD}_{600}$ in stationary phase adding $\mathrm{Ni}^{2+}$ (reached at different times). (b) Average growth rate with $\mathrm{Ni}^{2+}$ (c) Maximum $\mathrm{OD}_{600}$ in the stationary phase adding $\mathrm{Co}^{2+}$ (reached at different times). (d) Average growth rate with $\mathrm{Co}^{2+}$ (e). Maximum $\mathrm{OD}_{600}$ in stationary phase adding $\mathrm{As}^{5+}$ (reached at different times). (f) Average growth rate with $\mathrm{As}^{5+}$. (g) Maximum $\mathrm{OD}_{600}$ in the stationary phase adding $\mathrm{Li}^{+}$(reached at the same times). (h) Average growth rate with $\mathrm{Li}^{+}$. Plotted values are the mean of triplicate measurements, and error bars represent $\pm \mathrm{SD} .{ }^{*} p \leq 0.05 ;{ }^{* *} p \leq 0.01 ;{ }^{* * *} p \leq 0.001$. In grey, control without toxic metals; in white, with toxic metals. 
As lithium is widely distributed worldwide and has several industrial applications, it is important to know if $H f x$. mediterranei can grow in its presence. It is remarkable that this is the first study on the tolerance of lithium that has been carried out in Haloarchaea. In $\mathrm{Li}^{+}$tolerance assays, unexpected results were obtained. The cultures reached the same density in the stationary phase, ranging between 0.5 and $500 \mathrm{mM}$, indicating no difference from the control (Figure 5g). Therefore, Hfx. mediterranei R4 can grow in lithium's presence up to $0.5 \mathrm{M}$. The overall growth pattern upon exposure to $\mathrm{Li}^{+}$was not similar to the control, in fact, cultures reached a stationary phase before the control (Figure S8). The growth kinetics showed that the presence of these metals (toxic to most living beings) in the media resulted in a lower growth rate, except in $\mathrm{Li}^{\prime}$ s case (Figure 5/Table 5). Adding $\mathrm{Li}^{+}$resulted in a better growth rate and doubling time. Recently, the use of microorganisms in metal recovery has been increased; however, there is still little information about lithium's recovery [41]. In the future, proteomic or RNA-Seq approaches, among others, would help understand the mechanisms implicated in the tolerance of $\mathrm{Hfx}$. mediterranei to $\mathrm{Li}^{+}$and try to elucidate the strategy followed by this haloarchaeon to adapt to $\mathrm{Li}^{+}$. Its demand has been increased exponentially in the last years due to its applications in lithium-ion rechargeable batteries [42,43]. These batteries can be used to supply power for several portable electrical devices. It has applications in batteries and is also used in many items such as the manufacture of glass and ceramics or in the treatment of psychiatric disorders. Consequently, its recovery is a crucial subject, making $H f x$. mediterranei a great biotechnological application.

Table 5. Doubling time of Hfx. mediterranei growth in the presence of Ni, Co, As, or Li at different concentrations.

\begin{tabular}{ccccc}
\hline Heavy Metal & Concentration $(\mathbf{m M})$ & d.t. $(\mathbf{h}) *$ & $p$-Value & Summary \\
\hline- & - & $2.15 \pm 0.03$ & - & Control \\
\hline Nickel & 0.5 & $6.14 \pm 0.09$ & 0.001 & $* *$ \\
& 0.8 & $8.7 \pm 0.2$ & $<0.001$ & $* * *$ \\
& 1.2 & $16.6 \pm 0.4$ & $<0.001$ & $* * *$ \\
Cobalt & 1.6 & $31.9 \pm 1.6$ & $<0.001$ & $* * *$ \\
& 0.2 & $14.24 \pm 0.06$ & $<0.001$ & $* * *$ \\
& 0.4 & $24.1 \pm 0.2$ & $<0.001$ & $* * *$ \\
& 0.6 & $364.81 \pm 0.01$ & $<0.001$ & $* * *$ \\
Arsenic & 0.8 & $442.84 \pm 0.02$ & $<0.001$ & $* * *$ \\
& 1 & $533.19 \pm 0.01$ & $<0.001$ & $* * *$ \\
& 1.2 & $3465.73 \pm 0.02$ & $<0.001$ & $* * *$ \\
\hline Lithium & 2 & $6.28 \pm 0.03$ & 0.001 & $* *$ \\
& 4 & $28.1 \pm 0.2$ & $<0.001$ & $* * *$ \\
& 6 & $28.5 \pm 0.2$ & $<0.001$ & $* * *$ \\
& 8 & $40 \pm 1$ & $<0.001$ & $* * *$ \\
& 10 & $105 \pm 2$ & $<0.001$ & $* * *$ \\
\hline & 0.5 & $1.390 \pm 0.004$ & 0.13 & $*$ \\
& 2 & $1.426 \pm 0.003$ & 0.263 & ns \\
& 5 & $1.523 \pm 0.001$ & $>0.999$ & ns \\
& 20 & $1.437 \pm 0.004$ & 0.832 & ns \\
& 50 & $1.416 \pm 0.002$ & 0.065 & ns \\
& 250 & $1.865 \pm 0.002$ & $>0.999$ & ns \\
& 500 & $9.11 \pm 0.09$ & $<0.001$ & $* * *$ \\
\hline
\end{tabular}

ns: $p>0.05 ;{ }^{*} p \leq 0.05 ;{ }^{* *} p \leq 0.01 ;{ }^{* * *} p \leq 0.001 .{ }^{*} H f x$. mediterranei growth in liquid culture was assessed by optical density at $600 \mathrm{~nm}$, and doubling times during the exponential phase growth were calculated as described in the Materials and Methods section.

There are few studies of tolerance to Li; one of them has been carried out in Rhodococcus $\mathrm{sp}$. A5wh. This bacterium responds to lithium stress by overexpressing of stress proteins, proteins related to tricarboxylic acid cycle (TCA), and enzymes involved in the synthesis of compounds that can be used as osmoprotectants. Glutamine synthetase was overexpressed in the presence of $\mathrm{Li}$, and this enzyme catalyzes the condensation of glutamate 
and ammonia to glutamine, an amino acid involved in protein and purine synthesis. It can act as a carbon source to recharge the TCA [44]. In the case of Hfx. mediterranei, similar mechanisms to guarantee adaptation to the environment in response to Li may take place because this haloarchaeon grows faster in the presence of Li compared to the control.

\subsection{Detection of Intracellular Metal Ion Concentration Using ICP-MS}

The role of the tested metals during the stress response of Hfx. mediterranei was further investigated using the highly sensitive technique of ICP-MS. It was observed that $\mathrm{Co}^{2+}, \mathrm{Ni}^{2+}, \mathrm{Li}^{+}$, and $\mathrm{As}^{5+}$ were detected inside the cells in $\mathrm{Hm}-\mathrm{DM}$ (Table 6). The control (Hm-DM without metals) contained neither cobalt nor arsenic ( $0 \mathrm{mg} / \mathrm{Kg})$. However, nickel $(0.17 \mathrm{mg} / \mathrm{Kg})$ and lithium $(0.50 \mathrm{mg} / \mathrm{Kg})$ were present due to the sea water composition. Focusing on cobalt and nickel, increasing the metal's concentration to the culture medium increased the intracellular ion accumulation. In the case of lithium, its intracellular concentration increased to a maximum as there were no differences between the cultures with $\mathrm{Li} 250$ and $500 \mathrm{mM}$. It is demonstrated that $\mathrm{H} f x$. mediterranei can absorb $\mathrm{Li}^{+}, \mathrm{Co}^{2+}$, $\mathrm{As}^{5+}$, and $\mathrm{Ni}^{2+}$ within the cell, and future assays are needed to exploit the potential of this haloarchaeon in terms of its biotechnological applications.

Table 6. Detection of intracellular metal ion accumulation by inductively coupled plasma mass spectrometry (ICP-MS) in Hfx. mediterranei R4 cultured in Hm-DM.

\begin{tabular}{ccccc}
\hline Medium & Cobalt $(\mathbf{m g} / \mathbf{K g})$ & Nickel $(\mathbf{m g} / \mathbf{K g})$ & Lithium $(\mathbf{m g} / \mathbf{K g})$ & Arsenic $(\mathbf{m g} / \mathbf{K g})$ \\
\hline Control & $0.00 \pm 0.00$ & $0.17 \pm 0.00$ & $0.50 \pm 0.00$ & $0.00 \pm 0.00$ \\
\hline Co $0.2 \mathrm{mM}$ & $1.48 \pm 0.01$ & - & - & - \\
Co $1.2 \mathrm{mM}$ & $2.41 \pm 0.09$ & - & - & - \\
As $4 \mathrm{mM}$ & - & - & - & $0.17 \pm 0.09$ \\
Ni $0.5 \mathrm{mM}$ & - & $0.32 \pm 0.01$ & - & - \\
Ni $1.2 \mathrm{mM}$ & - & $1.37 \pm 0.15$ & $0.64 \pm 0.01$ & - \\
Li $12 \mathrm{mM}$ & - & - & $0.66 \pm 0.01$ & - \\
Li $50 \mathrm{mM}$ & - & - & $1.56 \pm 0.02$ & - \\
Li $250 \mathrm{mM}$ & - & - & $1.55 \pm 0.02$ & - \\
Li $500 \mathrm{mM}$ & - & - & & \\
\hline
\end{tabular}

\section{Conclusions}

This work was the first to catalogue how $H f x$. mediterranei can survive and grow under different extreme or stressful environmental conditions. It has been demonstrated that Hfx. mediterranei can adapt to harsh conditions such as low/high temperatures, low/high salt concentrations, changes in $\mathrm{pH}$, oxidative stress, and the addition of metals $\left(\mathrm{Ni}^{2+}, \mathrm{Li}^{+}\right.$, $\left.\mathrm{Co}^{2+}, \mathrm{As}^{5+}\right)$. Adapting to extreme conditions is an important advantage of living beings, considering, on one hand, that extreme adverse conditions are increasingly frequent due to climate change and, on the other hand, the possibility of developing new and promising biotechnological processes.

To sum up, Hfx. mediterranei grows optimally at $20 \%(w / v)$ of salt, $\mathrm{pH} 7.25$, and $42{ }^{\circ} \mathrm{C}$, although it can grow in a broader range of salt (10-35\% SW), $\mathrm{pH}(6.25-8.25)$, and temperature $\left(32-52{ }^{\circ} \mathrm{C}\right)$. These results indicate the use of this halophilic microorganism in diverse and interesting areas of study such as understanding its molecular adaptations and mechanisms against these stress conditions that are lethal to most living organisms; transcriptomic and proteomic analyses of salt, $\mathrm{pH}$, or temperature tolerance mechanisms; genetic engineering studies; and new biotechnological industrial applications such as the development of halotolerant enzymes and development of biochemical processes in media with high ionic strength, temperature, and acidic or basic $\mathrm{pHs}$.

According to this study, Hfx. mediterranei can tolerate $\mathrm{Li}^{+}, \mathrm{Co}^{2+}, \mathrm{As}^{5+}$, and $\mathrm{Ni}^{2+}$ at different concentrations in defined media, although each of these elements affect the specific growth rate of the microorganism in a particular way. The behavior of this microorganism in the presence of nickel and arsenic is similar to those described in other halophiles such as Hbt. salinarum or Halobacillus. The growth kinetics were more sensitive to cobalt and arsenic 
than for nickel and, especially, for lithium. Strikingly, Hfx. mediterranei can tolerate lithium concentrations up to $500 \mathrm{mM}$. Furthermore, its growth in the presence of $\mathrm{Li}^{+}$is better than in its absence, characterized by the shorter generation time. Furthermore, not only can it tolerate and grow in the presence of lithium, but it also incorporates it into its cellular interior. In light of these results, this haloarchaeaon is an excellent candidate to be used in biotechnology for the bioremediation of heavy metals in contaminated environments.

This work has shown that $H f x$. mediterranei can respond and adapt quickly to a multitude of adverse conditions. Therefore, it can be considered as a microorganism with a polyextremophilic character that is useful to develop new biotechnological applications. Further in-depth studies are necessary to elucidate its function and structural adaptation in greater detail against stress conditions in order to exploit its potential applications. The authors hope that this article will encourage other experts to investigate stress in Haloarchaea, to expand the knowledge of their natural environments, limitations, and mechanisms, and to adapt to these environmental shifts. Details about metal resistance and the utilization of Haloarchaea have been described here for first time; however, biotransformation of metals and novel bioremediation strategies remain uncovered. Although the current situation shows that haloarchaea are under-explored at the biotechnological level and their available information is scarce compared to other microorganisms living in non-halophilic environments, this work undoubtedly entails a great advance in this field.

Supplementary Materials: The following are available online at https:/ / www.mdpi.com/2076-260 7/9/2/336/s1, Figure S1: Growth of Hfx. mediterranei R4 under (•) standard culture conditions (20\% SW, $20 \mathrm{mM} \mathrm{NH}_{4} \mathrm{Cl}, 50 \mathrm{mM}$ MOPS, $0.03 \mathrm{mM} \mathrm{FeCl}_{3}, 7.5 \mathrm{mM} \mathrm{CaCl}_{2}, 22.75 \mathrm{mM}_{\text {glucose. The } \mathrm{pH} \text { was }}$ adjusted to 7.3 and grown at $42{ }^{\circ} \mathrm{C}$. No metal addition.) and under $(\bullet)$ salt stress conditions: (a) $10 \%$ SW; (b) $12.5 \%$ SW; (c) $15 \%$ SW; (d) $17.5 \%$ SW; (e) $22.5 \%$ SW; (f) $25 \%$ SW; (g) $27.5 \%$ SW; (h) $30 \%$ SW; (i) $32.5 \% \mathrm{SW}$, Figure S2: Growth of Hfx. mediterranei R4 under $(\bullet)$ standard culture conditions $(20 \%$ SW, $20 \mathrm{mM} \mathrm{NH}_{4} \mathrm{Cl}, 50 \mathrm{mM}$ MOPS, $0.03 \mathrm{mM} \mathrm{FeCl}_{3}, 7.5 \mathrm{mM} \mathrm{CaCl}_{2}, 22.75 \mathrm{mM}$ glucose. The $\mathrm{pH}$ was adjusted to 7.3 and grown at $42{ }^{\circ} \mathrm{C}$. No metal addition.) and under $(\bullet) \mathrm{pH}$ stress conditions: (a) $\mathrm{pH}$ 5.75; (b) pH 6.0; (c) pH 6.25; (d) pH 6.5; (e) pH 6.75; (f) pH 7.0; (g) pH 7.5; (h) pH 7.75; (i) pH 8.0; (j) $\mathrm{pH} 8.25$; (k) pH 8.5; (l) pH 8.75, Figure S3: Growth of Hfx. mediterranei R4 under (•) standard culture conditions (20\% SW, $20 \mathrm{mM} \mathrm{NH}_{4} \mathrm{Cl}, 50 \mathrm{mM}$ MOPS, $0.03 \mathrm{mM} \mathrm{FeCl}_{3}, 7.5 \mathrm{mM} \mathrm{CaCl}_{2}, 22.75 \mathrm{mM}$ glucose. The $\mathrm{pH}$ was adjusted to 7.3 and grown at $42{ }^{\circ} \mathrm{C}$. No metal addition.) and under $(\bullet)$ temperature stress conditions: (a) $32{ }^{\circ} \mathrm{C}$; (b) $37^{\circ} \mathrm{C}$; (c) $47^{\circ} \mathrm{C}$; (d) $52{ }^{\circ} \mathrm{C}$, Figure S4: Growth of Hfx. mediterranei R4 under ( •) standard culture conditions $\left(20 \% \mathrm{SW}, 20 \mathrm{mM} \mathrm{NH}_{4} \mathrm{Cl}, 50 \mathrm{mM} \mathrm{MOPS}, 0.03 \mathrm{mM} \mathrm{FeCl}_{3}, 7.5 \mathrm{mM} \mathrm{CaCl}_{2}\right.$, $22.75 \mathrm{mM}$ glucose. The $\mathrm{pH}$ was adjusted to 7.3 and grown at $42{ }^{\circ} \mathrm{C}$. No metal addition.) and under (•) oxidative stress conditions induced by $\mathrm{H}_{2} \mathrm{O}_{2}$ : (a) $2 \mathrm{mM} \mathrm{H}_{2} \mathrm{O}_{2}$; (b) $4 \mathrm{mM} \mathrm{H}_{2} \mathrm{O}_{2}$; (c) $6 \mathrm{mM} \mathrm{H}_{2} \mathrm{O}_{2}$; (d) $8 \mathrm{mM} \mathrm{H}_{2} \mathrm{O}_{2}$, Figure S5: Growth of $\mathrm{Hfx}$. mediterranei R4 under $(\bullet)$ standard culture conditions $(20 \%$ SW, $20 \mathrm{mM} \mathrm{NH}_{4} \mathrm{Cl}, 50 \mathrm{mM}$ MOPS, $0.03 \mathrm{mM} \mathrm{FeCl}_{3}, 7.5 \mathrm{mM} \mathrm{CaCl}_{2}, 22.75 \mathrm{mM}$ glucose. The $\mathrm{pH}$ was adjusted to 7.3 and grown at $42{ }^{\circ} \mathrm{C}$. No metal addition) and under $(\bullet)$ metal stress conditions induced by nickel: (a) $0.4 \mathrm{mM} \mathrm{Ni}^{2+}$; (b) $0.8 \mathrm{mM} \mathrm{Ni}^{2+}$; (c) $1.2 \mathrm{mM} \mathrm{Ni}^{2+}$; (d) $1.6 \mathrm{mM} \mathrm{Ni}^{2+}$, Figure S6: Growth of $\mathrm{Hfx}$. mediterranei R4 under $(\bullet)$ standard culture conditions $\left(20 \% \mathrm{SW}, 20 \mathrm{mM} \mathrm{NH}_{4} \mathrm{Cl}, 50 \mathrm{mM} \mathrm{MOPS}\right.$, $0.03 \mathrm{mM} \mathrm{FeCl}_{3}, 7.5 \mathrm{mM} \mathrm{CaCl}_{2}, 22.75 \mathrm{mM}$ glucose. The $\mathrm{pH}$ was adjusted to 7.3 and grown at $42{ }^{\circ} \mathrm{C}$. No metal addition.) and under $(\bullet)$ metal stress conditions induced by cobalt: (a) $0.2 \mathrm{mM} \mathrm{Co}^{2+}$; (b) 0.4 $\mathrm{mM} \mathrm{Co}^{2+}$; (c) $0.6 \mathrm{mM} \mathrm{Co}^{2+}$; (d) $0.8 \mathrm{mM} \mathrm{Co}^{2+}$; (e) $1.0 \mathrm{mM} \mathrm{Co}^{2+}$; (f) $1.2 \mathrm{mM} \mathrm{Co}^{2+}$, Figure S7: Growth of Hfx. mediterranei R4 under $(\bullet)$ standard culture conditions $(20 \%$ SW, $20 \mathrm{mM} \mathrm{NH} 4 \mathrm{Cl}, 50 \mathrm{mM}$ MOPS, $0.03 \mathrm{mM} \mathrm{FeCl} 3,7.5 \mathrm{mM} \mathrm{CaCl} 2,22.75 \mathrm{mM}$ glucose. The $\mathrm{pH}$ was adjusted to 7.3 and grown at $42{ }^{\circ} \mathrm{C}$. No metal addition.) and under (•) metal stress conditions induced by arsenic: (a) 2 mM As5+; (b) 4 mM As5+; (c) 6 mM As5+; (d) 8 mM As5+; (e) 10 mM As5+, Figure S8: Growth of Hfx. mediterranei $\mathrm{R} 4$ under $(\bullet)$ standard culture conditions $\left(20 \% \mathrm{SW}, 20 \mathrm{mM} \mathrm{NH}_{4} \mathrm{Cl}, 50 \mathrm{mM} \mathrm{MOPS}, 0.03 \mathrm{mM} \mathrm{FeCl}_{3}, 7.5\right.$ $\mathrm{mM} \mathrm{CaCl}_{2}, 22.75 \mathrm{mM}$ glucose. The $\mathrm{pH}$ was adjusted to 7.3 and grown at $42{ }^{\circ} \mathrm{C}$. No metal addition.) and under $(\bullet)$ metal stress conditions induced by lithium: (a) $0.5 \mathrm{mM} \mathrm{Li}^{+}$; (b) $2 \mathrm{mM} \mathrm{Li}^{+}$; (c) $5 \mathrm{mM} \mathrm{Li}^{+}$; (d) $20 \mathrm{mM} \mathrm{Li}^{+}$; (e) $50 \mathrm{mM} \mathrm{Li}^{+}$; (f) $250 \mathrm{mM} \mathrm{Li}^{+}$; (g) $500 \mathrm{mM} \mathrm{Li}^{+}$. 
Author Contributions: Conceptualization, L.M., J.E., and M.-J.B.; Methodology, L.M. and G.B.-B.; Formal analysis, L.M. and B.Z.; Investigation, L.M., J.E., and M.-J.B. Resources, M.C.; Writingoriginal draft preparation, L.M.; Writing-review and editing, L.M., M.C., B.Z., G.B.-B., J.E., and M.-J.B.; Supervision, J.E. and M.-J.B.; Project administration, M.-J.B.; Funding acquisition, M.-J.B. All authors have read and agreed to the published version of the manuscript.

Funding: This research was funded by Universidad de Alicante, VIGROB-016.

Institutional Review Board Statement: Not Applicable.

Informed Consent Statement: Not Applicable.

Acknowledgments: We would like to thank the Analysis Unit (SSTTI, University of Alicante) for performing the ICP-MS analysis.

Conflicts of Interest: The authors declare no conflict of interest.

\section{References}

1. de Macario, E.C.; Macario, A.J.L. Molecular biology of stress genes in methanogens: Potential for bioreactor technology. Adv. Biochem. Eng. Biotechnol. 2003, 81, 95-150. [CrossRef]

2. de Macario, E.C.; Macario, A.J. Stressors, stress and survival: Overview. Front. Biosci. 2000, 5, d780-d786. [CrossRef] [PubMed]

3. Quehenberger, J.; Shen, L.; Albers, S.V.; Siebers, B.; Spadiut, O. Sulfolobus-A potential key organism in future biotechnology. Front. Microbiol. 2017, 8, 2474. [CrossRef] [PubMed]

4. Gumulya, Y.; Boxall, N.J.; Khaleque, H.N.; Santala, V.; Carlson, R.P.; Kaksonen, A.H. In a quest for engineering acidophiles for biomining applications: Challenges and opportunities. Genes 2018, 9, 116. [CrossRef] [PubMed]

5. Donati, E.R.; Castro, C.; Urbieta, M.S. Thermophilic microorganisms in biomining. World J. Microbiol. Biotechnol. 2016, $32,179$. [CrossRef]

6. Oren, A. Microbial life at high salt concentrations: Phylogenetic and metabolic diversity. Saline Syst. 2008, 4, 2. [CrossRef] [PubMed]

7. Lledó, B.; Martínez-Espinosa, R.M.; Marhuenda-Egea, F.C.; Bonete, M.J. Respiratory nitrate reductase from haloarchaeon Haloferax mediterranei: Biochemical and genetic analysis. Biochim. Biophys. Acta Gen. Subj. 2004, 1674, 50-59. [CrossRef] [PubMed]

8. Andrei, A.S..; Banciu, H.L.; Oren, A. Living with salt: Metabolic and phylogenetic diversity of archaea inhabiting saline ecosystems. FEMS Microbiol. Lett. 2012, 330, 1-9. [CrossRef]

9. Rodriguez-Valera, F.; Juez, G.; Kushner, D.J. Halobacterium mediterranei spec, nov., a New Carbohydrate-Utilizing Extreme Halophile. Syst. Appl. Microbiol. 1983, 4, 369-381. [CrossRef]

10. Robinson, J.L.; Pyzyna, B.; Atrasz, R.G.; Henderson, C.A.; Morrill, K.L.; Burd, A.M.; Desoucy, E.; Fogleman Iii, R.E.; Naylor, J.B.; Steele, S.M.; et al. Growth Kinetics of Extremely Halophilic Archaea (Family Halobacteriaceae) as Revealed by Arrhenius Plots. J. Bacteriol. 2005, 187, 923-929. [CrossRef]

11. Shand, R.F.; Perez, A.M. Haloarchaeal Growth Physiology. In Enigmatic Microorganisms and Life in Extreme Environments; Springer: Dordrecht, The Netherlands, 1999; pp. 411-424. ISBN 978-94-011-4838-2.

12. D'Souza, S.E.; Altekar, W.; D'Souza, S.F. Adaptive response of Haloferax mediterranei to low concentrations of $\mathrm{NaCl}(<20 \%)$ in the growth medium. Arch. Microbiol. 1997, 168, 68-71. [CrossRef]

13. Oren, A.; Hallsworth, J.E. Microbial weeds in hypersaline habitats: The enigma of the weed-like Haloferax mediterranei. FEMS Microbiol. Lett. 2014, 359, 134-142. [CrossRef]

14. Torregrosa-Crespo, J.; Martínez-Espinosa, R.M.; Esclapez, J.; Bautista, V.; Pire, C.; Camacho, M.; Richardson, D.J.; Bonete, M.J. Anaerobic Metabolism in Haloferax Genus: Denitrification as Case of Study. Adv. Microb. Physiol. 2016, 68, 41-85. [CrossRef]

15. Rodrigo-Baños, M.; Garbayo, I.; Vílchez, C.; Bonete, M.J.; Martínez-Espinosa, R.M. Carotenoids from Haloarchaea and their potential in biotechnology. Mar. Drugs 2015, 13, 5508-5532. [CrossRef]

16. Mainka, T.; Mahler, N.; Herwig, C.; Pflügl, S. Soft sensor-based monitoring and efficient control strategies of biomass concentration for continuous cultures of Haloferax mediterranei and their application to an industrial production chain. Microorganisms 2019, 7, 648. [CrossRef]

17. Torregrosa-Crespo, J.; Pire, C.; Martinez-Espinosa, R.M.; Bergaust, L. Denitrifying haloarchaea within the genus Haloferax display divergent respiratory phenotypes, with implications for their release of nitrogenous gases. Environ. Microbiol. 2019, 21, 427-436. [CrossRef]

18. Zhao, Y.; Zhuang, X.; Ahmad, S.; Sung, S.; Ni, S.Q. Biotreatment of high-salinity wastewater: Current methods and future directions. World J. Microbiol. Biotechnol. 2020, 36, 37. [CrossRef]

19. Nájera-Fernández, C.; Zafrilla, B.; Bonete, M.J.; Martínez-Espinosa, R.M. Role of the denitrifying Haloarchaea in the treatment of nitrite-brines. Int. Microbiol. 2012, 15, 111-119. [CrossRef] [PubMed]

20. Thombre, R.S.; Shinde, V.D.; Oke, R.S.; Dhar, S.K.; Shouche, Y.S. Biology and survival of extremely halophilic archaeon Haloarcula marismortui RR12 isolated from Mumbai salterns, India in response to salinity stress. Sci. Rep. 2016, 6, 1-10. [CrossRef] [PubMed] 
21. Vargas-Amelin, E.; Pindado, P. The challenge of climate change in Spain: Water resources, agriculture and land. J. Hydrol. 2014, 518, 243-249. [CrossRef]

22. Domínguez, M.; Romera, R.; Sánchez, E.; Fita, L.; Fernández, J.; Jiménez-Guerrero, P.; Montávez, J.P.; Cabos, W.D.; Liguori, G.; Gaertner, M.Á. Present-climate precipitation and temperature extremes over Spain from a set of high resolution RCMs. Clim. Res. 2013, 58, 149-164. [CrossRef]

23. Giorgi, F. Climate change hot-spots. Geophys. Res. Lett. 2006, 33, 8707. [CrossRef]

24. Estrada, F.; Tol, R.S.J.; Botzen, W.J.W. Global economic impacts of climate variability and change during the 20th century. PLoS ONE 2017, 12, e0172201. [CrossRef]

25. Crist, E.; Mora, C.; Engelman, R. The interaction of human population, food production, and biodiversity protection. Science 2017, 356, 260-264. [CrossRef]

26. Pecl, G.T.; Araújo, M.B.; Bell, J.D.; Blanchard, J.; Bonebrake, T.C.; Chen, I.-C.; Clark, T.D.; Colwell, R.K.; Danielsen, F.; Evengård, B.; et al. Biodiversity redistribution under climate change: Impacts on ecosystems and human well-being. Science 2017, 355, eaai914. [CrossRef] [PubMed]

27. Cavicchioli, R.; Ripple, W.J.; Timmis, K.N.; Azam, F.; Bakken, L.R.; Baylis, M.; Behrenfeld, M.J.; Boetius, A.; Boyd, P.W.; Classen, A.T.; et al. Scientists' warning to humanity: Microorganisms and climate change. Nat. Rev. Microbiol. 2019, 17, 569-586. [CrossRef]

28. McGenity, T.J.; Gemmell, R.T.; Grant, W.D.; Stan-Lotter, H. Origins of halophilic microorganisms in ancient salt deposits. Environ. Microbiol. 2000, 2, 243-250. [CrossRef]

29. Rodríguez-Valera, F.; Ruiz-Berraquero, F.; Ramos-Cormenzana, A. Isolation of Extremely Halophilic Bacteria Able to Grow in Defined Inorganic Media with Single Carbon Sources. J. Gen. Microbiol. 1980, 119, 535-538. [CrossRef]

30. Bowers, K.J.; Wiegel, J. Temperature and pH optima of extremely halophilic archaea: A mini-review. Extremophiles 2011, 15, 119-128. [CrossRef]

31. Coker, J.A.; Moran-Reyna, A. The effects of extremes of $\mathrm{pH}$ on the growth and transcriptomic profiles of three haloarchaea. F1000Research 2014, 3, 168. [CrossRef]

32. Coker, J.A.; DasSarma, P.; Kumar, J.; Müller, J.A.; DasSarma, S. Transcriptional profiling of the model Archaeon Halobacterium sp. NRC-1: Responses to changes in salinity and temperature. Saline Syst. 2007, 3, 6. [CrossRef] [PubMed]

33. Sharma, K.; Gillum, N.; Boyd, J.L.; Schmid, A. The RosR transcription factor is required for gene expression dynamics in response to extreme oxidative stress in a hypersaline-adapted archaeon. BMC Genom. 2012, 13, 351. [CrossRef]

34. Voica, D.M.; Bartha, L.; Banciu, H.L.; Oren, A. Heavy metal resistance in halophilic Bacteria and Archaea. FEMS Microbiol. Lett. 2016, 363, fnw146. [CrossRef] [PubMed]

35. Völkel, S.; Fröls, S.; Pfeifer, F. Heavy metal ion stress on Halobacterium salinarum R1 planktonic cells and biofilms. Front. Microbiol. 2018, 9, 3157. [CrossRef]

36. Baati, H.; Siala, M.; Azri, C.; Ammar, E.; Dunlap, C.; Trigui, M. Resistance of a Halobacterium salinarum isolate from a solar saltern to cadmium, lead, nickel, zinc, and copper. Antonie Van Leeuwenhoek 2020, 113, 1699-1711. [CrossRef]

37. Nieto, J.J.; Ventosa, A.; Ruiz-Berraquero, F. Susceptibility of Halobacteria to Heavy Metals. Appl. Environ. Microbiol. 1987, 53, 1199-1202. [CrossRef]

38. Srivastava, P.; Kowshik, M. Mechanisms of metal resistance and homeostasis in Haloarchaea. Archaea 2013, $2013,732864$. [CrossRef]

39. Chen, W.; Jin, Y.; Zhao, J.; Liu, N.; Cui, Y. Nickel-hydrogen batteries for large-scale energy storage. Proc. Natl. Acad. Sci. USA 2018, 115, 11694-11699. [CrossRef] [PubMed]

40. Schippers, A.; Hedrich, S.; Vasters, J.; Drobe, M.; Sand, W.; Willscher, S. Biomining: Metal recovery from ores with microorganisms. Adv. Biochem. Eng. Biotechnol. 2014, 141, 1-47. [CrossRef] [PubMed]

41. Tsuruta, T. Removal and recovery of lithium using various microorganisms. J. Biosci. Bioeng. 2005, 100, 562-566. [CrossRef]

42. Owen, J.R. Rechargeable lithium batteries. Chem. Soc. Rev. 1997, 26, 259-267. [CrossRef]

43. Wakihara, M. Recent developments in lithium ion batteries. Mater. Sci. Eng. R Rep. 2001, 33, 109-134. [CrossRef]

44. Belfiore, C.; Curia, M.V.; Farías, M.E. Characterization of Rhodococcus sp. A5wh isolated from a high altitude Andean lake to unravel the survival strategy under lithium stress. Rev. Argent Microbiol. 2018, 50, 311-322. [CrossRef] [PubMed] 